\title{
Safety of research bronchoscopy, biopsy and bronchoalveolar lavage in asthma
}

\author{
W.J. Elston*,\#, A.J. Whittaker*, L.N. Khan*, P. Flood-Page*, C. Ramsay*, P.K. Jeffery", N.C. Barnes*
}

Safety of research bronchoscopy, biopsy and bronchoalveolar lavage in asthma. W.J. Elston, A.J. Whittaker, L.N. Khan, P. Flood-Page, C. Ramsay, P.K. Jeffery, N.C. Barnes. (C) ERS Journals Ltd 2004.

ABSTRACT: Bronchoscopy with endobronchial biopsy (EBB) and/or bronchoalveolar lavage (BAL) has become an important research tool in asthma. A recent report has suggested audit and reporting of the safety of these procedures.

A total of 159 asthmatic patients (84 males, 75 females), aged 18-52 (median 27) yrs, forced expiratory volume in one second 53-120 (median 88) \% predicted, underwent 273 bronchoscopies in six clinical research studies. On 228 occasions, EBB and BAL were performed and, on 45 occasions, EBB was performed alone. On 48 occasions, bronchoscopy was performed $24 \mathrm{~h}$ post-allergen challenge.

Adverse events occurred on 34 out of 273 occasions, none of which were following allergen challenge. Post-EBB and BAL, four patients developed pleuritic chest pain, shortness of breath and fever. A further two patients experienced pleuritic chest pain alone post-EBB/BAL. Bronchospasm or worsening of asthma symptoms occurred on 14 occasions, 13 post-EBB/BAL and on one occasion post-EBB alone. Fever/flu-like symptoms were reported on nine occasions following EBB and BAL. One subject had haemoptysis post-EBB/BAL, but required no intervention.

In conclusion, bronchoscopy, endobronchial biopsy and bronchoalveolar lavage can be performed safely in asthmatic patients. Most of the complications were seen where bronchoalveolar lavage and endobronchial biopsy were both performed, suggesting that bronchoalveolar lavage accounts for most of the adverse events.

Eur Respir J 2004; 24: 375-377.
*Dept of Respiratory Medicine, London Chest Hospital, and ${ }^{\#}$ Lung Pathology, Dept of Gene Therapy, Imperial College School of Medicine, Royal Brompton Hospital, London, UK.

Correspondence: N.C. Barnes

Dept of Respiratory Medicine

London Chest Hospital

Bonner Road

London E2 9JX

UK

Fax: 442089832279

E-mail: neil.barnes@bartsandthelondon.nhs.uk

Keywords: Adverse events

asthma

biopsy

bronchoalveolar lavage

bronchoscopy

Received: June 52003

Accepted after revision: April 232004

Financial support was provided by the British Lung Foundation, GlaxoSmithKline, Astra Zeneca, Merck and departmental funds.
Fibreoptic bronchoscopy with endobronchial biopsy (EBB) or bronchoalveolar lavage (BAL) has become an important tool in asthma research over the last two decades. These techniques have led to significant advances in the understanding of the pathogenesis of asthma and, in particular, the role of inflammatory cells and mediators [1-4]. In addition, intervention studies with new and existing treatments have provided useful insight into the mechanisms of action and efficacy of these treatments [5-7]. Following initial concerns over the safety of these techniques in asthmatic patients [8,9], consensus guidelines were published by the National Heart, Lung and Blood Institute [10, 11]. More recently, three papers have reported bronchoscopy to be safe and well-tolerated in a relatively small number of asthmatic patients [12-14]. Despite this, concerns still remain and a recent report has suggested audit and continued reporting of the safety of these procedures. The current authors report their experience of adverse events related to fibreoptic bronchoscopy performed in asthmatic subjects taking part in six clinical research studies.

\section{Methods}

\section{Study subjects}

A total of 159 patients with asthma (84 males, 75 females), forced expiratory volume in one second (FEV1) 53-120 (median 88) \% predicted, aged 18-52 (median 27) yrs were recruited for six studies and underwent a total of 273 bronchoscopies. On 228 occasions, subjects underwent EBB and BAL, 48 of which were performed $24 \mathrm{~h}$ post-allergen challenge. On 45 occasions, subjects had EBB alone. Subjects were recruited from chest clinics at the London Chest and Royal Brompton Hospitals (London, UK), advertisements in local press and from primary care. Ethics committee approval for each study was obtained from the research ethics committees of the relevant hospitals and each subject gave written informed consent. Eligible subjects were males or females, aged 18-52, with a clear clinical history of asthma, reversible airflow obstruction spontaneously or following $\beta_{2}$-agonists, histamine provocative concentration causing a $20 \%$ fall in FEV1 $\left(\mathrm{PC}_{20}\right)<8 \mathrm{mg}$ or a history of mild asthma precipitated by an aeroallergen (entry criteria depending on the individual study).

PC20 was measured for three of the studies; for one study, the data was not recorded, but entry criteria included a PC20 $<4 \mathrm{mg}$. For the other two studies, PC20 ranged from 0.06-6.0 (median 1.0). In the multicentre studies, only subjects who underwent bronchoscopy at the London Chest Hospital or the Royal Brompton Hospital are included in this report.

Study 1 was a multicentre, double-blind, randomised, placebo-controlled, parallel group study using an antiinterleukin-5 monoclonal antibody. This study required subjects to undergo two bronchoscopies, with EBB and BAL 8 weeks apart [15]. 
Study 2 was a multicentre, randomised, double-blind, placebo-controlled parallel group study investigating the effects of zafirlukast and beclomethasone dipropionate on allergen-induced airway inflammation. Subjects underwent bronchoscopy with EBB and BAL on two occasions 8 days apart and, on the second occasion, the bronchoscopy was performed $24 \mathrm{~h}$ post-allergen challenge [16].

Study 3 was a randomised, placebo-controlled study to examine whether cyclosporin A inhibited allergen-induced airway inflammation. Subjects underwent two bronchoscopies with $\mathrm{EBB}$ and BAL 3 days apart; the second was performed $24 \mathrm{~h}$ post-allergen challenge [17].

Study 4 was a multicentre, randomised, placebo-controlled comparison of the effects of oral pranlukast on bronchial mucosal immunopathology. Subjects underwent two bronchoscopies with EBB and BAL 12 weeks apart.

Study 5 was a single-centre study to compare the inflammatory profile in asthmatic smokers and nonsmokers. Subjects had one bronchoscopy with EBB alone.

Study 6 was a randomised, double-blind, placebocontrolled study investigating the effects of montelukast on eosinophils in bronchial biopsy specimens. Subjects underwent two bronchoscopies with EBB and BAL 6 weeks apart.

\section{Bronchoscopy}

Fibreoptic bronchoscopy was performed on an outpatient basis at the London Chest Hospital and Royal Brompton Hospital in accordance with established guidelines [11]. Following an overnight fast, patients were admitted to the day-case unit and baseline observations were performed. All bronchoscopies were performed in the morning. Patients were premedicated with $2.5-5 \mathrm{mg}$ nebulised salbutamol. Immediately before bronchoscopy, midazolam was administered i.v. via a cannula, which remained in situ until the patient was fully recovered. Subjects in studies 4 and 6 also received $600 \mu \mathrm{g}$ atropine as a pre-med. During the procedure, subjects had continuous monitoring of pulse oximetry (Nellcor Symphony N-300; Nellcor Puritan Bennett, Pleasanton, CA, USA) and received oxygen via nasal cannulae as required to maintain oxygen saturations $>93 \%$. The nose and oropharynx were anaesthetised with lignocaine spray, the vocal cords with 4\% lignocaine delivered via the bronchoscope and the tracheobrochial tree with $2 \%$ lignocaine delivered via the bronchoscope. The bronchoscope, either a Pentax FB 19 TX (Pentax, Tokyo, Japan) or an Olympus mode OSE (Olympus Corp., Lake Success, NY, USA) was inserted nasally where possible and the oral route was used as a second choice. After inspection of the bronchial tree when BAL was performed, $60-180 \mathrm{~mL}$ (depending on the study) of prewarmed $0.9 \%$ saline were instilled into the right middle lobe and then gently aspirated. Bronchial biopsies were then obtained from the subsegmental carinae of the right or left lower lobes or right middle lobe. Following bronchoscopy, subjects were observed with regular monitoring of oximetry and vital signs. Patients were discharged after an observation period of $\geqslant 2 \mathrm{~h}$, once safe swallowing had returned and observations were satisfactory. All were given an emergency contact number and follow-up was performed within a week of the procedure on most occasions. Adverse events were documented either at the time of bronchoscopy or at follow-up.

\section{Results}

Adverse events occurred on 34 out of 273 occasions; none of these were following allergen challenge (table 1). There
Table 1.-Adverse events

Adverse event EBB/BAL EBB alone Total

Occasions $n$

Bronchospasm during procedure

Bronchospasm pre-discharge

Worsening asthma post-discharge

Fever/influenza-like illness

Pleuritic chest pain

Pleuritic chest pain/SOB/fever

Lethargy/malaise

Nonspecific chest pain

Bleeding

Total

$\begin{array}{ccc}228 & 45 & \\ 2 & 0 & 2 \\ 6 & 0 & 6 \\ 5 & 1 & 6 \\ 9 & 0 & 9 \\ 2 & 0 & 2 \\ 4 & 0 & 4 \\ 1 & 1 & 2 \\ 2 & 0 & 2 \\ 1 & 0 & 1 \\ 32 & 2 & 34\end{array}$

Data are presented as n. EBB: endobronchial biopsy; BAL: bronchoalveolar lavage; SOB: shortness of breath.

were no differences in adverse events between subjects receiving placebo and active drug. Where subjects had two bronchoscopies, there were no differences in the frequency of adverse events during the first or second bronchoscopy. On one occasion, a subject who experienced pleuritic chest pain following the first bronchoscopy withdrew from the study and, thus, declined to have a further bronchoscopy.

Four patients developed pleuritic chest pain, fever and shortness of breath within 12-24 h of EBB and BAL. Two of these had changes on chest radiograph consistent with pneumonitis and required hospital admission. They were treated with $i . v$. antibiotics, to cover possible infection, and nebulised bronchodilators and were discharged after 2 days. Oral antibiotics were continued to complete a 1-week course. One patient experienced pleuritic chest pain and breathlessness $24 \mathrm{~h}$ post-procedure when, as a result of technical problems with suction equipment during BAL, only $\sim 10 \%$ of the BAL fluid was recovered. These symptoms were associated with a fall in FEV1 from $88 \%$ to $70 \%$ pred. Symptoms and spirometry resolved within 6 days without any treatment. One patient experienced chest pain and shortness of breath with no radiological changes and no treatment was required. Two further patients experienced pleuritic chest pain alone, without fever or dyspnoea.

Bronchoconstiction episodes or worsening of asthma symptoms occurred on 14 occasions, 13 post-EBB/BAL and once post-EBB alone. On two occasions, the patient experienced problems during the procedure, and the procedure was terminated to allow treatment with nebulised bronchodilators and $i . v$. steroids. On six occasions, the symptoms occurred prior to discharge and required treatment with nebulised bronchodilators, and six subjects experienced an increase in symptoms within $2448 \mathrm{~h}$ post-discharge and required the additional use of inhaled salbutamol for 3-25 days.

Fever or flu-like symptoms were reported on nine occasions following EBB and BAL. On each occasion, the symptoms that started $12-24 \mathrm{~h}$ after the procedure were short-lived and settled spontaneously with no treatment in 2-5 days. Nonspecific chest discomfort occurred on two occasions postEBB/BAL. A minor haemoptysis occurred on one occasion post-EBB/BAL; the subject was admitted for observation overnight and no treatment was required. Two patients reported general lethargy/malaise for 1 week post-bronchoscopy, one after $\mathrm{EBB}$ alone and one post-EBB/BAL. 
acceptable safety profile in asthmatics of mild-to-moderate severity. To our knowledge, this is the largest series reporting the safety of research bronchoscopies in asthmatic subjects. A low incidence of adverse events has been found and it has been shown that the procedure is well-tolerated by the majority of subjects. Most of the adverse events experienced by the studied patients were minor, requiring no specific treatment and with no prolonged morbidity.

On two occasions following bronchoscopy with biopsy and BAL, subjects required hospital admission. On each occasion, they complained of pleuritic chest pain and fever, and developed chest radiograph infiltrates consistent with a diagnosis of pneumonitis. Treatment was instituted with i.v. antibiotics to cover possible infection and both subjects were fit to be discharged after 2 days. There were no long-term sequelae in either case.

On a further nine occasions, patients reported fever or flulike symptoms. These events are not specific to asthmatic patients; fever following bronchoscopy is well-recognised, with previous studies estimating an incidence of $1.2-16 \%[18$, 19] for all bronchoscopic procedures and an incidence of $2.5-50 \%$ amongst patients undergoing BAL [20, 21]. In the current patients, only those undergoing BAL experienced fever or pneumonitis, and subjects who only had biopsy performed reported only nonspecific side-effects, such as mild deterioration in asthma symptoms and general lethargy. This would suggest that BAL accounts for the majority of adverse events and, although a direct comparison cannot be made as a result of the relatively small numbers of subjects undergoing biopsy alone, this is in keeping with the findings of HUMBERT et al. [14] who observed a trend towards a smaller reduction in peak expiratory flow when only biopsies were taken.

No adverse events were reported in the 48 patients who had bronchoscopy post-allergen challenge, suggesting that bronchoscopy can be safely performed following allergen challenge. This is consistent with previous studies. GIANORIO et al. [22] showed that BAL performed either 4 or $24 \mathrm{~h}$ postallergen challenge neither deteriorated lung function nor increased airway responsiveness in a group of atopic patients with a history of rhinitis and/or bronchial asthma.

Bronchoscopy with endobronchial biopsy and/or bronchoalveolar lavage has become an important research tool. It can be performed safely and is well-tolerated by asthmatic subjects. Continued surveillance and reporting of the use of these techniques is recommended.

\section{References}

1. Jeffery PK, Wardlaw AJ, Nelson FC, Collins JV, Kay AB. Bronchial biopsies in asthma. An ultrastructural, quantitative study and correlation with hyperreactivity. Am Rev Respir Dis 1989; 140: 1745-1753.

2. Djukanovic R, Roche WR, Wilson JW, et al. Mucosal inflammation in asthma. Am Rev Respir Dis 1990; 142: 434 457.

3. Bousquet J, Chanez P, Lacoste JY, et al. Eosinophilic inflammation in asthma. N Engl J Med 1990; 323: 10331039.

4. Robinson DS, Hamid Q, Ying S, et al. Predominant TH2like bronchoalveolar T-lymphocyte population in atopic asthma. N Engl J Med 1992; 326: 298-304.

5. Djukanovic R, Wilson JW, Britten KM, et al. Effect of an inhaled corticosteroid on airway inflammation and symptoms in asthma. Am Rev Respir Dis 1992; 145: 669-674.

6. Jeffery PK, Godfrey RWA, Adelroth E, Nelson F, Rogers A, Johansson S-A. Effects of treatment on airway inflammation and thickening of basement membrane reticular collagen in asthma. A quantitative light and electron microscopic study. Am Rev Respir Dis 1992; 145: 890-899.

7. Sullivan PJ, Bekir S, Jaffar Z, Page C, Costello J. Antiinflammatory effects of low dose oral theophylline in atopic asthma. Lancet 1994; 343: 1006-1008.

8. Rosenow EC, Andersen HA. Bronchoscopically induced bronchospasm. Chest 1976; 70: 565-566.

9. Albertini RE, Harrell JH 2nd, Kurihara N, Moser KM. Arterial hypoxemia induced by fiberoptic bronchoscopy. JAMA 1974; 230: 1666-1667.

10. National Institutes of Health workshop summary. Summary and recommendations of a workshop on the investigative use of fiberoptic bronchoscopy and bronchoalveolar lavage in individuals with asthma. J Allergy Clin Immunol 1985; 76: 145-147.

11. Workshop summary and guidelines: investigative use of bronchoscopy, lavage and bronchial biopsies in asthma and other airway diseases. J Allergy Clin Immunol 1991; 88: 808814.

12. Djukanovic R, Wilson JW, Lai CK, Holgate ST, Howarth $\mathrm{PH}$. The safety aspects of fiberoptic bronchoscopy, bronchoalveolar lavage, and endobronchial biopsy in asthma. Am Rev Respir Dis 1991; 143: 772-777.

13. Van Vyve T, Chanez P, Bousquet J, Lacoste JY, Michel FB, Godard P. Safety of bronchoalveolar lavage and bronchial biopsies in patients with asthma of variable severity. Am Rev Respir Dis 1992; 146: 116-121.

14. Humbert M, Robinson DS, Assoufi B, Kay AB, Durham SR. Safety of fibreoptic bronchoscopy in asthmatic and control subjects and effect on asthma control over two weeks. Thorax 1996; 51: 664-669.

15. Flood-Page PT, Menzies-Gow AN, Kay AB, Robinson DS. Eosinophil's role remains uncertain as anti-interleukin-5 only partially depletes numbers in asthmatic airway. $\mathrm{Am}$ J Resp Crit Care Med 2003; 167: 199-204.

16. Macfarlane AJ, Manning PJ, Ryan M, et al. Effects of zafirlukast and beclomethasone on allergen induced airway inflammation in asthma. Thorax 2004 (in press).

17. Khan LN, Kon OM, Macfarlane AJ, et al. Attenuation of the allergen induced late asthmatic reaction (LAR) by cyclosporin A (CsA) is associated with inhibition of bronchial eosinophil, interleukin-5, granulocyte macrophage colony-stimulating factor and eotaxin. Am J Respir Crit Care Med 2000; 162: 1377-1382.

18. Pereira W, Kovnat D, Snider GL. A prospective cooperative study of complications following flexible fiberoptic bronchoscopy. Chest 1978; 73: 813-816.

19. Pereira W, Kovnat D, Khan MA, Iacovino JR, Spivack ML, Snider GL. Fever and pneumonia after flexible fiberoptic bronchoscopy. Am Rev Respir Dis 1975; 112: 59-64.

20. Strumpf IJ, Feld MK, Cornelius M, Keogh BA, Crystal RG. Safety of fiberoptic bronchoalveolar lavage in evaluation of interstitial lung disease. Chest 1981; 80: 268-271.

21. Pingleton SK, Harrison G, Stechschulte DJ, Wesselius LJ, Kerby GR, Ruth WE. Effect of location, pH and temperature of instillate in bronchoalveolar lavage in normal volunteers. Am Rev Respir Dis 1983; 128: 1035-1037.

22. Gianiorio $\mathrm{P}$, Bonavia $\mathrm{M}$, Crimi $\mathrm{E}$, et al. Bronchial responsiveness is not increased by bronchoalveolar lavage performed after allergen challenge. Am Rev Respir Dis 1991; 143: $105-108$. 